\title{
Da crise ecológica e sua relação com a pandemia de coronavírus (Covid-19): uma reflexão à luz do projeto da ética da responsabilidade em Hans Jonas
}

\section{On the ecological crisis and its relation with the coronavirus (Covid- 19) pandemic: a reflection in light of Hans Jonas' ethics of responsibility}

Otávio Oliveira Silva ${ }^{1}$

Danielson Aleixo ${ }^{2}$

\section{Resumo}

Esta pesquisa teórica de natureza qualitativa, desenvolvida a partir de levantamento e análise bibliográfica, pretende apresentar uma possível relação entre a existência da crise sanitária de Coronavírus Covid-19, como reflexo da crise ecológica à luz do projeto ético do princípio responsabilidade proposto por Hans Jonas (1903-1993). Para isso, parte-se da seguinte questão: em que medida é possível estabelecer uma relação entre a crise sanitária de Covid-19 como reflexo da crise ecológica à luz da teoria do projeto da ética da responsabilidade em Hans Jonas? Nossa hipótese, apoiada em Jonas, é de que a crise sanitária atual, resultado do desmedido progresso técnico-científico empregado pelo capital econômico, desde a modernidade na exploração da natureza, representa um alerta social dramático, em razão de suas consequências destrutivas para o futuro da humanidade e da biosfera, o que implica para o presente de nossa "civilização tecnológica" um dever de responsabilidade coletiva de preservação da natureza, respeitando-a como ser de dignidade própria, e uso prudente do saber técnico-científico, condição sine qua non para a manutenção de toda a vida na Terra.

\footnotetext{
${ }^{1}$ Mestrando do Programa de Pós-graduação em Cultura e Sociedade - PgCult (Universidade Federal do Maranhão). Bolsista pela FAPEMA: Fundação de Amparo à Pesquisa e ao Desenvolvimento Tecnológico no Maranhão, 2020-2021.

E-mail: otavio.silva@discente.ufma.br

${ }^{2}$ Graduando do Curso de Ciências Biológicas da Universidade Federal do Pará.
} 


\section{2 | Dossiê - Natureza e Sociedade no Antropoceno - Superando a Separação?}

Palavras-chave: Hans Jonas. Crise sanitária. Natureza. Ética. Responsabilidade.

\section{Abstract}

This qualitative theoretical research, developed from bibliographic survey and analysis, intends to present a possible relationship between the existence of the health crisis of Coronavirus Covid-19, as a reflection of the ecological crisis in the light of the ethical project of the principle of responsibility proposed by Hans Jonas (1903-1993). For this, we start from the following question: to what extent is it possible to establish a relationship between the health crisis in Covid-19 as a reflection of the ecological crisis in the light of the theory of the project of the ethics of responsibility in Hans Jonas? Our hypothesis, supported by Jonas, is that the current health crisis, the result of the immense technical-scientific progress employed by economic capital, since modernity in the exploration of nature, represents a dramatic social alert, due to its destructive consequences for the future of humanity and the biosphere, which implies for the present of our "technological civilization" a duty of collective responsibility for the preservation of nature, respecting it as a being of its own dignity, and prudent use of technical and scientific knowledge, a sine qua non condition for the maintenance of all life on Earth.

Keywords: Hans Jonas. Health crisis. Nature. Ethics. Responsibility.

\section{Introdução}

Os recentes surtos epidêmicos no século XXI, como a atual crise sanitária de Coronavírus Covid-19, parecem revelar um forte vínculo entre o agir humano e a degradação dos sistemas ecológicos. O agir humano pautado pelo emprego desmedido do conhecimento técnico-científico aplicado em escala industrial pelo modelo de capital econômico na exploração da natureza, pode ser mensurado como principal produtor do aquecimento global. Entretanto, essa relação ainda é minimizada ou deixada em segundo plano como reflexo da crise ecológica global. Os governos e as sociedades ainda pouco problematizam a causa da crise sanitária como consequência econômica da destruição humana na natureza, bem como sobre formas sustentáveis de se relacionar com ela.

Nessa perspectiva, a partir da obra "O princípio responsabilidade: ensaio de uma ética para uma civilização tecnológica” (1979), sobretudo, da abordagem do capítulo V “A responsabilidade Hoje: o futuro ameaçado e a ideia de progresso”, esta 
pesquisa teórica de natureza qualitativa, desenvolvida a partir de levantamento e análise bibliográfica, pretende apresentar uma reflexão possível sobre a crise sanitária de Coronavírus Covid-19 como reflexo da crise ecológica, resultante da interação desmedida das ações antrópicas de exploração econômica dos recursos naturais, cujo processo se remete a consequências advindas do progresso científico inaugurado na modernidade3.

No decorrer do século XVI em diante a mentalidade mecanicista considerando a natureza como máquina capaz de ser dominada, produziu um imaginário de poder sobre a mesma, cuja consequência prática tem causado impactos agressivos na estrutura de equilíbrio da vida no planeta. 4 Com isso, a construção do capitalismo é marcada pelo progresso da ciência agregado a destruição de vários ecossistemas, sobretudo, a partir do século XVIII com a primeira Revolução Industrial. Seguindo ao longo do século XIX, mas, sobretudo, no século XX, onde os impactos deste poder positivista se constituem em uma ameaça mundial a sobrevivência, quando do acontecimento das guerras mundiais, época vivida por Hans Jonas5.

Nesse contexto, este trabalho trata de uma pesquisa inicial sobre as implicações filosóficas do projeto de Hans Jonas acerca dos impactos do progresso técnico-científico sobre a vida humana e a natureza, tendo na existência da covid19 um elemento constituinte desse processo, uma vez que, sua existência parece estar vinculada ao avanço destrutivo do agir humano sobre áreas ecológicas para

\footnotetext{
3 "O princípio responsabilidade: ensaio de uma ética para uma civilização tecnológica" é um dos escritos mais relevantes do século XX, porque problematiza as ações humanas no âmbito da ciência e da técnica na relação da vida humana com a natureza, cuja pauta tem se tornado uma evidente preocupação na contemporaneidade. Publicado originalmente em 1979, a obra apresenta uma divisão de 06 capítulos. Contudo, nosso objetivo consiste em discutir algumas ideias apresentadas no capitulo V, intitulado: "A responsabilidade hoje: o futuro ameaçado e a ideia de progresso". Em razão de se tratar de um trabalho especulativo, temos a clara consciência de suas limitações, mas também de sua importância no cenário de pesquisas que exploram as reflexões sobre o agir humano e a crise ecológica.

$4 \mathrm{O}$ que marca a mentalidade mecanicista na modernidade? Podemos dizer que a comprovação do Heliocentrismo, agregado à invenção do método experimental matemático através de Galileu Galilei (1564-1642), a ascensão de forças políticas e econômicas burguesas e seu ideal de lucro, o declínio da Escolástica e da metafísica aristotélica, constituem alguns dos principais fatores de construção de uma mentalidade mecanicista, fundamentalmente baseado no dualismo sujeito/objeto de Descartes (1596-1650). Nesse contexto, observa Koyré (2006, p. 1): “[...] durante esse período o espírito humano, ou pelo menos o europeu, sofreu uma revolução profunda, que alterou o próprio quadro e padrões de nosso pensamento, e da qual a ciência e a filosofia modernas são, a um só tempo, raiz e fruto".

5 No século XX, época das bombas atômicas que arrasaram as cidades de Hiroshima e Nagasaki no Japão. Hans Jonas traz a luz reflexões acerca do perigo do mau uso do saber técnico-cientifico sobre a vida no planeta, cujo abuso de poder demonstra ser a face perigosa de sua criação.
} 


\section{4 | Dossiê - Natureza e Sociedade no Antropoceno - Superando a Separação?}

fins de obtenção de lucro e outros fatores. Neste sentido, a presente pesquisa trata do seguinte problema: em que medida é possível estabelecer uma relação entre a pandemia de (Covid-19) como reflexo da crise ecológica à luz da teoria ética do princípio responsabilidade em Hans Jonas?

De maneira metodológica, o trabalho apresenta três seções, primeiramente contextualizamos a construção do saber científico e as consequências da constituição da imagem do homem como "senhor da natureza" na modernidade, em segundo lugar, discutimos sua vinculação com a crise ecológica, correlacionando a existência da pandemia como elemento constituinte desse processo e, por fim, estabeleceremos sua relação com o princípio da ética da responsabilidade proposta pelo autor.

\section{Do homem como "Senhor da natureza"}

Sabe-se que a vida humana e toda a biosfera terrestre perpassam por um processo apocalítico no século XXI. Pois, o modelo econômico capitalista avança vorazmente no controle técnico-científico da natureza, produzindo violência, desigualdades e desequilíbrios ecológicos num modo de vida insustentável. Sendo fonte do aquecimento global, onde espécies desaparecem, rios são poluídos, florestas são desmatadas, solos são degradados, etc., Porém, que possíveis processos estão relacionados ao imaginário de dominação existente, pelo qual o homem ocidental explora a natureza sem lhe conceder outro valor a não ser o da "utilidade econômica"?

Para responder essa questão é preciso discutir, mesmo que, sem a devida profundidade necessária, a construção da mentalidade cientifica na modernidade. Pois, é com a constituição da imagem do homem como "senhor da natureza" na modernidade europeia que o saber cientifico produzido se traduz em desejo de dominação da mesma, na medida em que o saber do sujeito moderno vai se traduzindo em ações de posse do objeto conhecido. De acordo com Jonas (2006) é inspirado na invenção do "programa baconianino" que o ser humano inicia o processo, cuja proposta de saber visa exatamente ao controle da natureza para subjugá-la:

[...] colocar o saber a serviço da dominação da natureza e utilizá-la para melhorar a sorte da humanidade- não contou desde suas origens, na sua execução capitalista, com a racionalidade e a retidão que lhe seriam adequadas; porém, sua dinâmica de êxito, que conduz obrigatoriamente 
aos excessos de produção e consumo, teria subjugado qualquer sociedade [...] (JONAS, 2006, p. 235).

Para Jonas (2006) o agir de nossa espécie perturba o equilíbrio do planeta, o que revela um perigo para toda a biosfera. Ameaça, sobretudo, contida no "ideal baconiano da fórmula saber é poder”, consistindo no principio do êxito excessivo da técnica. Sua invenção impôs o controle da natureza. Sob o curso do êxito demasiado técnico-industrial capitalista, a serviço da subjugação da natureza, vivenciamos na atualidade uma condição apocalíptica, onde o êxito econômico multiplicou a produção, conduzindo ao consumo metabólico entre "o corpo social e o ambiente natural”, conforme argumenta Jonas (2006, p. 235):

A ameaça do ideal baconiano de dominação da natureza por meio da
técnica reside, portanto, na magnitude de seu êxito. Esse êxito tem duplo
aspecto: econômico e biológico. A inter-relação de ambos, que conduz
necessariamente à crise é hoje patente. [...] Esse fato, por si só, já trazia o
perigo do esgotamento dos recursos naturais [...] Mas, o êxito biológico,
do qual incialmente se tinha menos consciência potencializou e acelerou o
perigo: o aumento numérico desse mesmo corpo coletivo metabolizante,
ou seja, o crescimento exponencial da população na esfera de influência da
civilização técnica, estendendo-se recentemente para todo o planeta.

Diante do poder conquistado, a espécie humana explodiu demograficamente criando uma superpopulação, que por sua vez, está conduzindo a uma superexploração do planeta. Sua capacidade de resistência está posta em jogo pelo agir humano, em razão do êxito econômico construído pelo pregresso técnico, vez que segundo Jonas (2006, p. 236): “[...] ameaça o homem e sua obra. Bacon não poderia imaginar um paradoxo desse tipo: [...] o poder tornou-se autônomo, enquanto sua promessa, transformou-se em uma ameaça e sua perspectiva de salvação, em apocalipse”.

A pretensão humana de domínio da natureza, colocou-a sob segundo plano. Pois, o desenvolvimento das ciências naturais "encheu os olhos" dos modernos como sinônimo de progresso e aperfeiçoamento civilizatório. Para Viana (2007) a técnica moderna se constitui de um "duplo movimento" que privilegia a "potencialização do sujeito" e "desvaloriza a natureza"6. Segundo o autor, essa cisão

\footnotetext{
${ }^{6}$ Para o mesmo autor, antes de Jonas se preocupar com o objeto da técnica, "Heidegger foi o primeiro a denunciar a técnica como a servidora da potencialização do sujeito" (VIANA, 2010, p. 108).
} 


\section{6 | Dossiê - Natureza e Sociedade no Antropoceno - Superando a Separação?}

foi iniciada inconscientemente por Francis Bacon (1561-1626) no século XVII, com a publicação da obra "Nova Atlântida" (1627) 7:

O "projeto de Bacon" sintetiza bem o espírito com o qual nasceu a técnica moderna: conquistar a Natureza, submetê-la ao poder do homem. Este espírito de "conquista" da Natureza revela uma marca fundamental da filosofia moderna que a separa uma vez por todas da medieval, a saber: a potencialização do Sujeito. O Eu foi a grande descoberta dos Modernos de Descartes a Hegel (VIANA,2010, p. 107).

Não obstante, o sucesso desse projeto filosófico-matemático fundamentada em critérios de ideias "claras e distintas" do método cartesiano, operacionalizou o "endeusamento" da Ciência, deixando de lado a reflexão ética sobre seu uso ${ }^{8}$. Disso decorre a "desqualificação" do valor intrínseco da natureza, pois segundo Santos (1995, p. 32): “o rigor científico, porque fundado no rigor matemático, [...] ao quantificar, desqualifica, [...] ao objetivar os fenômenos, [...] os degrada, [...] os caricaturiza, [...] e finalmente, destrói a personalidade da natureza”.

A invenção da ciência experimental na modernidade modificou o modo do homem interagir na natureza, ao criar condições capazes de explicar seu funcionamento, transformou seu imaginário, ou seja, instrumentalizando-a o homem se pensa como "senhor da natureza", segundo Koyré (2006, p. 1) essa revolução cientifica: "transformou o homem de espectador em proprietário e senhor da natureza”. Nessa perspectiva se reportando a esse processo como “ilusão da razão moderna”, observa Fernandes (2002, p. 56):

Esta ilusão da razão moderna quebra os laços do homem com a natureza, dado que esta é encarada como estando ao serviço do homem na imediaticidade das relações de causa efeito. Esta perde o mistério e a grandiosidade. Aparece, então, como um mero reservatório inesgotável de matérias-primas e energia de que a humanidade pode dispor sem qualquer limitação.

\footnotetext{
7 Segundo Zaterka e Barbosa (2017, p. 211): “[...] O conhecimento e o avanço nas ciências, vinculados a uma nova noção de progresso, fazem da Nova Atlântida de Bacon uma importante obra para as futuras utopias após o século XVII; pois a construção dessa modernidade por vias tecnológicas são entrelaçadas nesse livro".

${ }^{8}$ A perspectiva cartesiana do "método" ('dúvida) abalou a relação do homem consigo mesmo e com a natureza, uma vez que, trouxe muitos problemas ao perceber a realidade como um "conjunto de forças mecânicas". Pois, sob esse enfoque, o pensamento cartesiano que coloca "o mundo como objeto", dentro de uma perspectiva de "conhecer por conhecer", consequente, transforma a Natureza em "coisa ou objeto" que pode ser estudada e controlada pelos mecanismos de pesquisa e assim modificadas para o proveito humano, com efeito, citamos Descartes (2013, p. 52, grifo nosso): “[...] o que mais me contentava nesse método é que por ele eu tinha certeza de usar em tudo minha razão, se não perfeitamente, ao menos da melhor maneira possível: além disso, eu sentia, praticando-o, que meu espirito se acostumava aos poucos a conceber mais claramente e mais distintamente seus objetos $[\ldots] "$.
} 
A nova mentalidade produziu de acordo com Koyré (2006) "a destruição do cosmos e a geometrização do espaço", onde o modelo mecânico causal substitui o “modelo metafísico teleológico". Neste sentido, as mudanças ocorridas nos século XVI e XVII em diante constituíram um processo de transformação que modificou para sempre a relação do homem com o mundo e consigo mesmo, pois segundo Koyré (2006, p. 5): “[...] Enquanto o homem medieval e o antigo visavam a pura contemplação da natureza e do ser, o moderno deseja a dominação e a Subjugação".

O progresso da ciência desencadeou a dessacralização da natureza, ou seja, sua dissociação de dependência e integração do homem com a mesma. Subjugandoa explicações matemáticas o homem se pensa "senhor da natureza". Esse poder se fundamenta, sobretudo, nos êxitos das descobertas científicas das ciências naturais, vez que, “[...] o perigo decorre da dimensão excessiva da civilização técnicoindustrial, baseada nas ciências naturais" (JONAS, 2006, p. 235).

Para Santos (1995) através do projeto mecanicista, uma das bases da ideia de progresso pelo qual, por exemplo, a burguesia conseguiu status de poder, torna-se possível prever e intervir no real. Segue-se daí toda justificação económica para sua potencial exploração. Pois, "Esta ideia do mundo-máquina é de tal modo poderosa que vai se transformar na grande hipótese universal da época moderna, o mecanicismo [...] e que é o grande sinal de ascensão intelectual da burguesia” (SANTOS, 1995, p. 17).

Os efeitos desse processo perpassam pelo iluminismo no século XVIII e a razão instrumental, tendo seu auge, sobretudo, na contemporaneidade com o positivismo do século XIX. Durante este longo processo, o homem moderno dessacraliza a natureza sujeitando as forças naturais ao cálculo matemático. Contudo, observa Fernandes (2002, p. 28): “Ao fascínio suscitado, no século XIX, pelas aplicações da ciência, sucede um século XX alarmado com as aplicações da ciência no campo militar que alteraram radicalmente as relações entre a vida e a morte no mundo ocidental”.

Neste sentido, os benefícios dos conhecimentos produzidos pela ciência e pela técnica são indiscutíveis, contudo, seu modo de utilização pode produzir consequências destrutivas para a vida. Em razão disso, segundo Santos (1995, p. 5): "Vivemos num tempo atônito", ou seja, para Santos (1995) vivemos um tempo ambíguo, porque os progressos científicos representam uma ordem 


\section{8 | Dossiê - Natureza e Sociedade no Antropoceno - Superando a Separação?}

"paradoxalmente dramática” na medida em que proporcionam avanços e melhorias, também proporcionam "retrocessos profundos" 9, pois:

[...] fazem-nos crer [...] uma sociedade de comunicação e interativa libertada das carências e inseguranças que compõem os dias de muitos de nós. [...] por outro lado, [...] os limites do rigor científico combinada com os perigos [...] da catástrofe ecológica ou da guerra nuclear- fazem-nos temer que o século XXI termine antes de começar (SANTOS, 1995, p. o6).

Para Dupas (2007) o progresso é um mito carregado de ideologia das classes dominantes, interessado em nos fazer crer que a história tem destino certo e glorioso. O que a crise ecológica, as mudanças climáticas e as desigualdades revelam o contrário. A técnica faz a natureza ser subjugada aos nossos critérios para fins puramente egoístas de exploração. É no século XVIII que o progresso acelera o processo de opressão que destrói a percepção do valor intrínseco da natureza. "A Revolução Industrial foi o marco da mudança de tendência, quando se começou a queimar pesadamente carvão e óleo, produzindo os gases causadores do efeito estufa” (DUPAS, 2007, p. 85).

Nessa perspectiva, para Dupas (2007, p. 73, grifo do autor): “[...] esse progresso, discurso dominante das elites globais, traz também consigo exclusão, concentração de renda, subdesenvolvimento e graves danos ambientais, agredindo e restringindo direitos humanos essenciais”. Com isso, o crescimento econômico exacerbado baseado no progresso científico parecer ser o grande vilão, pelo qual o atual modelo de desenvolvimento exploratório humano coloca em risco a vida planetária, ao assumir um uso desmedido do saber.

Neste sentido, os agravamentos dos problemas ecológicos abarcam uma reflexão sobre o agir humano. Pois, a instrumentalização da natureza progrediu sem estabelecer cuidado e respeito para com a mesma. E, além disso, o progresso associado à lógica do capital converte-se em desigualdade e exploração, porque beneficia uns enquanto outros sobrevivem na miséria do sistema, modo de vida que coloca em risco a própria Civilização e a vida na biosfera. O que significa dizer que, a crise ecológica pode ser pensada como uma crise ética, uma vez que, o agir humano no presente pode afetar a sobrevivência de gerações futuras. Por isso,

\footnotetext{
9 A obra de Santos (1995) intitulada "Um Discurso sobre as Ciências" foi publicada na década de 80, especificamente em 1987, sua proposta apresenta uma crítica ao paradigma da epistemologia positivista construída na modernidade. Com efeito, em razão de ter sido publicada nessa época, o autor se refere ao século XXI se remetendo a uma perspectiva de futuro.
} 
segundo Fernandes (2002, p. 25): "Jonas faz a apologia de um uso comedido e prudente da ciência e da técnica, não a sua eliminação”.

Para Viana (2010, p. 110): “A ameaça da técnica advém do fato de que o novo poder do Sujeito não foi acompanhado por uma nova sabedoria capaz de gerar também um novo comportamento". Com isso, apesar de trazer benefícios civilizatórios, se desprendeu da reflexão ética, trazendo consequências climáticas, sociais, porque converteu o poder tecnológico em ameaça, ou seja, dominou o mundo a serviço do homem, sem se preocupar com a intervenção e o impacto climático na biosfera.

O que revela a ambiguidade do argumento do progresso, pois não é de todo rumo ao aperfeiçoamento da civilização, dado o grau de ameaça a vida hoje vigente. Pois segundo Viana (2010, p. 110): “[...] O problema é que ninguém havia questionado se a Natureza mesma teria condições de dar sempre, sem nenhum limite. Hoje somos conscientes do limite! A crise ecológica que enfrentamos representa o grito da Natureza denunciando o abuso".

Diante desse breve recorte histórico e da mentalidade constituída pelo saber técnico-científico ao longo da modernidade e seu impacto na dessacralização natureza, iremos discutir no segundo momento deste trabalho, a vinculação desse contexto mais detalhadamente com a crise ecológica, correlacionando a existência da pandemia de Covid-19, como possível elemento constituinte desse processo. A atual crise sanitária de covid-19 marca do ano de 2020, é evidentemente ameaçadora, conforme o seu potencial destrutivo e ainda desconhecido. Porém, argumenta Junges (2020, p. 36): “uma grave crise sanitária provocada por algum vírus potente e desconhecido era esperada e anunciada, apenas não se sabia quando".

\section{Da crise sanitária de coronavírus (Covid-19) como elemento da crise ecólogica}

Segundo Lowy (2013) em texto intitulado "crise ecológica, crise capitalista, crise de civilização: a alternativa ecossocialista” a crise ecológica é resultante do processo exploratório da civilização industrial, responsável pela causa do aquecimento global: o crescimento demográfico exacerbado; poluição da água e ar; esgotamento dos solos; desmatamento; extinção de espécies; desertificação, 
destruição da camada de ozônio, dentre outros, o que lhe confere atenção central no capitalismo, nas palavras do autor,

A questão da ecologia, do meio ambiente, é a questão central do capitalismo; [...] se você não quer falar do capitalismo, não adianta falar do meio ambiente, porque a questão da destruição, da devastação, do envenenamento ambiental é produto do processo de acumulação do capital (LOWY, 2013, p. 81).

Sob a lógica do lucro opera uma mentalidade de controle técnico-científico sobre a natureza, que se remete ao que Webber (1992) chamou na modernidade de "desencantamento do mundo" que retira o sentido explicativo das forças sagradas ou mágicas sobre a natureza, em prol de uma visão de domínio. Esse modo de racionalidade mecanicista agregado ao modo de vida da civilização industrial sob o signo da mercadoria, acelerou a destruição da natureza, no qual o homem deixa de se vê como parte integrante da mesma, mas como dono ou "senhor" dela, conforme Webber (1992, p. 165), esse “desencantamento” significa:

[...] não há forças misteriosas incalculáveis, mas que podemos, em princípio, dominar todas as coisas pelo cálculo. Isto significa que o mundo foi desencantado. Já não precisamos recorrer aos meios mágicos para dominar ou implorar aos espíritos, como fazia o selvagem, para quem esses poderes misteriosos existiam. Os meios técnicos e os cálculos realizam o serviço.

Para Kopenawa, Xamã Yanomani na obra a "Queda do Céu”, é preciso modificar o olhar sobre a natureza no presente, para que todos tenham um futuro. Suas palavras são de crítica à civilização ocidental, mas também de convite à proteção da natureza. Para eles, a natureza não é mercadoria, mas ser vivo sagrado e princípio da vida, conforme as palavras de Kopenawa e Albert (2015.p. 64-65): "Gostaria que os brancos parassem de pensar que nossa floresta é morta e que ela foi posta lá a toa. [...] quem sabe assim eles queiram defendê-las conosco? [...] Porque se a floresta for completamente devastada, nunca mais vai nascer outra”.

Esse engajamento pela preservação dos sistemas ecológicos requer luta, resistência e sensibilidade no que diz respeito à preservação da natureza, dado que, por exemplo, no contexto brasileiro, infelizmente, as intensões governamentais seguem caminhos outros que o da preservação, já que as políticas governamentais (de quase todos os governos) pretendem deixar "a boiada passar", conforme sugeriu a triste fala do Ministro do Meio Ambiente Ricardo Salles em reunião ministerial 
em abril de 2020, visando desregulamentar as leis ambientais, "para favorecer grileiros, desmatadores, madeireiras, o agronegócio” ( ALESSI, 2020) ${ }^{10}$.

O que revela total insensibilidade do Estado quanto aos impactos ecológicos na natureza, nesse contexto, citamos Kopenawa e Albert (2015.p. 64-65),

Os brancos não pensam muito adiante no futuro. [...] é por isso que eu gostaria que eles ouvissem minhas palavras. [...] "Os Yanomani são gente diferente de nós, e, no entanto, suas palavras são retas e claras! [...] $\mathrm{O}$ pensamento deles segue caminhos outros que o da mercadoria. [....] Querem defender sua terra porque desejam continuar vivendo nela como antigamente. [...] Se eles não a protegerem, seus filhos não terão lugar para viver felizes. [...] já que só terão deixado para eles uma terra, nua e queimada, impregnada de fumaça e epidemia e cortada por rios de água sujas!”.

Para Lowy (2013, p. 80): “[...] o processo de devastação da natureza, [...] se acelerou a tal ponto que não estamos mais discutindo um futuro a longo prazo. Estamos discutindo processos que já estão em curso - a catástrofe já começa, esta é a realidade". Para Welzer (2010) na obra "Guerras climáticas: porque mataremos e seremos mortos no século XXI”, a crise ecológica representa um apocalipse climático responsável por potencializar ainda mais os conflitos sociais, num mundo marcadamente desigual, no qual o agravamento da crise ecológica converte- se em guerra.

Nesse contexto, podemos perceber que, claramente o quão ambientes equilibrados são necessários à preservação da vida dos seres vivos, uma desordem nesse equilíbrio pode gerar consequências catastróficas, por isso, alguns pesquisadores sugerem que atualmente vivenciamos uma época denominada Antropoceno, em razão do impacto avassalador do homem na natureza'11. Com isso, a atual crise sanitária pode evidentemente ser pensada como reflexo desse processo de degradação da natureza.

\footnotetext{
${ }^{10}$ ALESSI, Gil. "Salles vê "oportunidade" com coronavírus para "passar de boiada" desregulação da proteção ao meio ambiente". El País. São Paulo, 22 de maio. de 2020. Disponível em: <https://brasil.elpais.com/brasil/2020-05-22/salles-ve-oportunidade-com-coronavirus-parapassar-de-boiada-desregulacao-da-protecao-ao-meio-ambiente.html $>$. Acesso em: 20 de out. de 2020.

${ }^{11}$ Segundo Artaxo (2014) a ideia do Antropoceno começou a nascer recentemente com alguns pesquisadores na década de 80, cuja época a humanidade começou a sentir "os efeitos" globais do aquecimento do planeta. Contudo, é nos anos 2000, precisamente com Paul Crutzen que o termo ganha notoriedade no campo cientifico, pois: "O prêmio Nobel de Química (1995) Paul Crutzen auxiliou na popularização do termo nos anos 2000, através de uma série de publicações discutindo o que seria essa nova era geológica da Terra [...]. A humanidade emerge como uma força significante globalmente, capaz de interferir em processos críticos de nosso planeta, como a composição da atmosfera e outras propriedades" (ARTAXO, 2014, p. 15).
} 
O que significa que a continuidade do atual modo de vida centrado na exploração desmedida do planeta tem um preço insustentável: a continuidade da vida. Pois, segundo Jonas (2006, p. 269): “[...] há um preço que se paga por esse progresso: com cada ganho se perde algo valioso. Não é necessário lembrar que o custo humano e animal da civilização é alto, e com o progresso, tende a aumentar". Disso decorre algo inquestionável, sem sustentabilidade da biodiversidade o aparecimento e a reprodução de vírus serão cada vez mais notórios, conforme explica Junges (2020, p. 43):

\begin{abstract}
Quanto mais diversidade biológica tiver num ecossistema, mais dinâmicos são os processos de interação desse bioma e mais facilmente ele se recupera de efeitos de desequilíbrios ambientais que estão na origem do surgimento do vírus; todavia, quanto menor é a biodiversidade ecossistêmica, mais dificuldade ele terá para criar as condições vitais para a reprodução da vida e mais dificilmente ele conseguirá reconfigurar a rede vital que protege contra a disseminação do vírus.
\end{abstract}

De acordo com dados do relatório (PNUMA) Programa das Nações Unidas para o Meio Ambiente de 2016, essa situação consiste em uma questão de preocupação global. Segundo o relatório a média de doenças infeciosas de natureza zoonótica, atingindo os seres humanos está se intensificando, surgindo em "média três novas doenças" a cada ano, sendo que "75\% delas são zoonóticas", tais como: "a [...] SARS (2002); a Influenza Aviária ou Gripe Aviária (2004); o H1N1 ou a Gripe Suína (2009); a Síndrome Respiratória do Oriente Médio ou MERS (2012); o Ebola (2014- 2015); o Zika Vírus (2015-2016); e a Febre do Nilo Ocidental (2019)" (PNUMA, 2016) ${ }^{12}$.

Essa constatação de claro desequilíbrio pode ser responsável por esse conjunto de novas doenças recentes, ao passo que, pode explicar como fundamentalmente à preservação da biodiversidade pode proteger os ecossistemas e minimizar a ocorrência de disseminação de vírus entre a espécie humana, assim como, representa argumento inquestionável para preservação dos sistemas ecológicos, por isso, segundo Junges (2020, p. 43):

[...] é necessário repensar o modo como os atores dessa sociedade tratam e se relacionam com a natureza, porque o surgimento da pandemia está relacionado com a crise ambiental. [...] a natureza não pode ser reduzida a um banco de recursos naturais disponíveis ao extrativismo, mas

\footnotetext{
${ }^{12}$ Causas do Covid-19 incluem ações humanas e degradação ambiental, apontam estudos. PNUMA, Brasília, 22 de maio de 2020. Disponível em: https://www.unenvironment.org/pt-br/noticias-ereportagens/reportagem/causas-do-covid-19-incluem-acoes-humanas-e-degradacao-ambiental. Acesso em: 15 de out. de 2020.
} 
considerada a nossa casa comum, nosso fundo comum que preserva as condições vitais (oxigênio, equilíbrio do clima, regime de chuvas, metabolismo dos detritos) para a reprodução da vida.

Nesta perspectiva, o desequilíbrio causado pela espécie humana, talvez seja responsável pelas zoonoses, como a pandemia de COVID-19, uma zoonose relacionada à destruição dos ecossistemas naturais, pelo qual animais silvestres passam a conviver em contato com as populações humanas e a inseri-los em suas dietas, talvez tenha sido isso a causa grave de disseminação da crise sanitária do Coronavírus surgida na China em dezembro de 2019, conforme explica, Junges (2020, p. 36):

[...] o crescente desmatamento e a maior proximidade dos humanos com animais selvagens, com o agravante do consumo de sua carne, que parece ter sido o caso do pangolin na China, permite essa passagem do vírus, típico de determinado animal, para os humanos.

Essa situação permitiu que provavelmente um patógeno, um vírus de alta capacidade de mutação genética, fosse capaz de facilmente passar de uma espécie a outra e provocar novas doenças, em razão da exploração desmedida dos recursos naturais, conforme argumenta o educador e ecólogo, André Murtinho Ribeiro Chaves, "Esta gênese da COVID-19 situa muito bem a degradação ambiental proveniente da lógica capitalista de exploração sem limites do ser humano e dos recursos naturais" (CHAVES, 2020, grifo do autor) ${ }^{13}$.

Contudo, essa crise sanitária e ecológica talvez seja uma resposta do planeta as alterações provocadas pela destruição humana de seu equilíbrio, porém, infelizmente ainda pouco ouvida por governos e sociedades ocidentais. Por outro lado, essa realidade implica uma oportunidade de repensar a liberdade humana a partir das consequências negativas trazidas pelo progresso técnico-científico ao longo da modernidade sobre os ecossistemas da natureza e seus impactos na própria vida humana. Com isso, passaremos a discussão do próximo e último tópico deste trabalho.

\footnotetext{
${ }^{13}$ CHAVES, André M. R. A crise ecológica como causa e consequência da COVID-19: entre a vida e a morte. Anticapitalista- Medium. Cananeia, o9 de maio de 2020. Disponível em: https://medium.com/@psolanticapitalista/a-crise-ecol\%C3\%B3gica-como-causa-econsequ\% $3 \%$ AAncia-da-covid-19-entre-a-vida-e-a-morte-5172bd6dc5e2. Acesso em: 25 de out. de 2020.
} 


\section{Sobre o projeto do princípio da ética da responsabilidade em Hans} Jonas

Com base na discussão anterior, acerca da crise ecológica e a existência da crise sanitária de Covid-19, como evidente resultado do desmedido agir humano sobre a natureza potencializado no contexto do perigo do desenvolvimento da ciência e da técnica na modernidade, apontaremos na última parte deste trabalho, a relevância do projeto do princípio da ética da responsabilidade, proposta por Hans Jonas no cuidado da vida humana e da biosfera.

O projeto da ética da responsabilidade nasce do medo do progresso, cujo temor da extinção da espécie humana é um dado real e ameaçador. Jonas metaforicamente compara o poder do saber técnico-científico ao mito de Prometeu, cuja audácia de levar fogo aos homens, foi punido por Zeus a ter o fígado sempre comido por uma águia, após ser restaurado todos os dias. A metáfora do prometeu desacorrentado, significa que o conhecimento técnico-científico necessita de "freios voluntários”, ou seja, da reflexão ética, para que o prometeu (saber técnicocientifico) não produza a "desgraça para nós mesmos", fazendo uma referência ao uso da ciência desprendido da ética:

\footnotetext{
O prometeu definitivamente desacorrentado, ao qual a ciência confere forças inimagináveis e a economia um impulso infatigável, clama por uma ética que, por meio de freios voluntários, impeça o poder dos homens de se transformar em uma desgraça para eles mesmos [...] a promessa da tecnologia moderna se converteu em ameaça, ou essa se associou a aquela de forma indissolúvel (JONAS, 2006, p. 21).
}

Nessa perspectiva, citamos Costa (2020, p. 158): "Se por um lado muito se errou no passado, no presente a regra deve ser mitigar os danos para que, no mínimo, se tire lições para o futuro”. É sobre essa preocupação com o futuro da humanidade e da natureza, pelo qual Jonas propôs sua teoria ética- A ética da responsabilidade- para pensar a preocupação do perigo do uso da ciência e da técnica decorrente, sobretudo, do contexto advindo das guerras mundiais e seu impacto na vida do planeta, pelo qual o abuso do conhecimento técnico-científico aliado ao capital, além de produzir guerras representa uma ameaça a toda vida no mundo, em razão da predatória forma de exploração dos recursos naturais.

Conforme aponta Fernandes (2002, p. 22), 
[...] o homem da época moderna teve êxito no seu empreendimento, mas a época contemporânea sofre também os impactos negativos. A desregulação dos fenómenos naturais, o esgotamento dos recursos energéticos e matérias-primas, as catástrofes naturais e a exclusão social mostram ao homem os limites do seu projecto.

Esse processo histórico contradiz o discurso positivista de que o conhecimento científico seria sinônimo evidente de evolução e progresso, mas sim pode ser prejudicial, pois, apesar de trazer benefícios civilizatórios, se desprendeu da reflexão ética, trazendo consequências climáticas, ecológicas e sociais. Por isso, necessitamos da construção de mudança de mentalidade baseada na responsabilidade ambiental.

Se a espécie humana depende sua existência da natureza, bem como toda a biosfera e dos processos que compõem o seu equilíbrio natural, florestas, águas limpas, oxigênio puro, e outros elementos. Então, essa lição parte do respeito aos limites da natureza e de sua vulnerabilidade, pois de acordo com Jonas (2006, p. 229): “[...] a natureza conserva sua dignidade, que se contrapõem ao arbítrio do nosso poder. Na medida em que ela nos gerou, devemos fidelidade à totalidade de sua criação".

Para Jonas (2006) a "civilização tecnológica" é destrutiva de si, em razão de sua manutenção biológica que se revela egoísta, e pelo modo de vida centrado na liberdade de produção técnica que se tornou ameaçadora à vida, pois o modo de vida humano é causa de sua própria destruição, “[...] na medida em que o homem se tornou perigoso não só para si, mas para toda a biosfera" (JONAS, 2006, p. 229).

$\mathrm{O}$ fato de ser uma espécie dominante revela o risco da presença humana no planeta Terra. Com isso, observa Jonas (2006, p. 231): "A "natureza" não poderia ter corrido um risco maior do que este de haver produzido o homem". Contudo, o fato de interpretar sua presença na biosfera como "perigosa", significa que essa situação que lhe impõem pensar que:

O futuro da humanidade é o primeiro dever do comportamento coletivo humano na idade da civilização técnica, que se tornou "todo-poderosa" no que tange ao seu potencial de destruição. Esse futuro da humanidade, inclui, obviamente, o futuro da natureza como sua condição sine qua non (JONAS, 2006, p. 229, grifo do autor).

Tendo em vista isso, Jonas postula segundo França e Oliveira (2016, p. 103): "a necessidade de pensar uma nova ética, tendo em vista que as éticas do passado não dão conta dos problemas causados pela técnica, que põe a vida em constante 
ameaça de destruição". Por isso, diante do perigo, há "solidariedade de destino [...] recém-revelada pelo perigo que ambos correm" (JONAS, 2006, p. 230).

Nesse contexto, para Jonas (2006) o progresso desmedido da "civilização técnica" é insustentável devido às disputas sociais para com o acesso e uso dos recursos naturais. Tal situação a favor da destruição deveria gerar o medo quanto as consequências catastróficas do agir humano, o que os intérpretes da filosofia de Jonas denominam de Heurística do medo, assim comentada por Battestin e Ghiggi (2010, p. 76, grifo dos autores):

Quanto mais próximo do futuro estiver aquilo que deve ser temido, mais a Heurística do medo se torna necessária. O medo se torna a primeira obrigação preliminar de uma ética da responsabilidade. É do medo fundado que deriva a atitude ética fundamental, repensada a partir da vontade de evitar o pior.

Nesse sentido, para Jonas (2006) pensar a preservação da natureza é condição coletiva para a manutenção biológica da existência humana e da própria natureza enquanto ser que a gerou. Enquanto causa geradora da vida, a natureza tem o direito de reclamar nossa proteção. O que implica para o presente de nossa “civilização tecnológica” um dever de responsabilidade coletiva de preservação da natureza, respeitando-a como ser de dignidade própria, e uso prudente do saber técnico-científico, para a manutenção de toda a vida na Terra.

O que precisa ficar claro é notória dependência do homem em relação a natureza, porque este faz parte dela, não podendo existir, sem “desfigurar" sua imagem fora dela. Disso decorre que, o dever sobre a existência humana deve incluir o dever sobre a natureza, reportando a ela práticas de respeito, conforme argumenta Jonas (2006, p. 230): [...] "se o dever em relação ao homem se apresenta como prioritário, ele deve incluir o dever em relação à natureza, como condição de sua própria continuidade e como um dos elementos de sua própria integridade existencial”. Com efeito, argumentam Battestin e Ghiggi (2010, p. 74):

\footnotetext{
Hans Jonas determinou o Princípio Responsabilidade como sendo uma ética em que o mundo animal, vegetal, mineral, biosfera e estratosfera passam a fazer parte da esfera da responsabilidade. A reflexão sobre a incerteza da vida futura é resultante de um equívoco cometido ao isolar o ser humano do restante da natureza (sendo o homem a própria Natureza). Somente uma ética fundamentada na magnitude do ser, poderia ter um significado real e verdadeiro das coisas em si.
}

O princípio responsabilidade postula uma concepção de uma nova ética, ou 
seja, um novo imperativo distinto do kantiano, “[...] Aja de modo a que os efeitos da tua ação sejam compatíveis com a permanência de uma autêntica vida humana sobre a Terra" (JONAS, 2006, p. 47). Para Jonas, o cuidado com a natureza é centrada numa mudança de mentalidade, pautada pelo dever coletivo de conceber dignidade a mesma, percebendo-a como parte integrante dela, e lhe reportando práticas de respeito à sua existência, pois “[...] Nascido do perigo, esse dever clama, sobretudo, por uma ética da preservação e da proteção, e não por uma ética do progresso ou do aperfeiçoamento" (JONAS, 2006, p. 232).

\section{Considerações finais}

De acordo com a pesquisa apresentada, a mentalidade mecanicista constituída no da modernidade provocou uma dessacralização da integração do homem como parte da natureza. Essa mentalidade agregada à prática capitalista levou a um uso descomedido dos recursos naturais ao limite. O que significa que a continuidade do atual modo de vida centrado na exploração desmedida do planeta tem um preço insustentável: a continuidade da vida. Com isso, argumentamos que a crise sanitária pode ser pensada como resultado de todo um processo complexo que envolve a destruição da natureza a partir das consequências de dessacralização da mesma.

O desequilíbrio causado pela espécie humana, sobretudo, através do impacto do progresso técnico-científico e o evidente critério de uso dos recursos naturais ao extremo, talvez seja responsável pelas zoonoses, como a pandemia de COVID-19, uma zoonose relacionada à destruição dos ecossistemas naturais. Por outro lado, essa crise sanitária e ecológica talvez seja uma resposta do planeta as alterações provocadas pela destruição humana de seu equilíbrio que se remete ao modo de vida da civilização industrial.

Diante da realidade pandêmica que vive a contemporaneidade neste início de século XXI parece evidente que, a atual crise sanitária que vivemos, revela um drástico alerta em relação à continuidade da vida. Parar o desmatamento das florestas, incentivar o reflorestamento, diminuir a criação de gado, usar de forma prudente os conhecimentos em ciência e tecnologia de forma ética para com a preservação da vida, entre outras, parece apenas uma das razões para que ocorram 
mudanças na vida prática do modo de vida capitalista, em relação a estes desequilíbrios.

O que parece fundamentalmente se exigir em todo o percurso apresentado apoiado no pensamento jonasiano, é uma mudança de mentalidade, baseada no medo das consequências do progresso técnico-científico para se refletir e agir no presente, tal como pensado por Jonas, uma vez que, a natureza tem o direito de reclamar nossa proteção. O que para Jonas (2006) implica para o presente de nossa "civilização tecnológica" um dever de responsabilidade coletiva de preservação da natureza, respeitando-a como "ser de dignidade própria, condição sine qua non para a manutenção de toda a vida na Terra".

\section{Referências}

ALESSI, Gil. "Salles vê "oportunidade" com coronavírus para "passar de boiada" desregulação da proteção ao meio ambiente". El País. São Paulo, 22 de maio. de 2020. Disponível em: <https://brasil.elpais.com/brasil/2020-05-22/salles-veoportunidade-com-coronavirus-para-passar-de-boiada-desregulacao-da-protecaoao-meio-ambiente.html>. Acesso em: 20 de out. de 2020.

ARTAXO, Paulo. Uma nova era geológica em nosso planeta: o Antropoceno? REVISTA USP, São Paulo. n. 103, p. 13-24, 2014. Disponível em: http://www.revistas.usp.br/revusp/issue/view/7488. Acesso em: 10 de nov. de 2020.

BATTESTIN, Cláudia; GHIGGI, Gomercindo. O princípio responsabilidade de Hans Jonas: um princípio ético para os novos tempos. Revista Thaumazein, v. $3, \mathrm{n}^{\mathrm{o}}$. 6, p. $69-85, \quad 2010 . \quad$ Disponível em: https://periodicos.ufn.edu.br/index.php/thaumazein/article/view/164. Acesso em: 15 de nov. de 2020.

Causas do Covid-19 incluem ações humanas e degradação ambiental, apontam estudos. PNUMA, Brasília, 22 de maio de 2020. Disponível em: https://www.unenvironment.org/pt-br/noticias-ereportagens/reportagem/causas-do-covid-19-incluem-acoes-humanas-edegradacao-ambiental. Acesso em: 15 de out. de 2020.

CHAVES, André M. R. A crise ecológica como causa e consequência da COVID-19: entre a vida e a morte. Anticapitalista- Medium. Cananeia, o9 de maio de 2020. Disponível em: https://medium.com/@psolanticapitalista/a-criseecol\% 3 3\%B3gica-como-causa-e-consequ $\% \mathrm{C}_{3} \% A A n c i a-d a-c o v i d-19-e n t r e-a-v i d a-$ e-a-morte-5172bd6dc5e2. Acesso em: 25 de out. de 2020.

COSTA, Lucas de A. N. O desastre nada natural do covid-19. In: YOUNG, Carlos E. F; MATHIAS, João Felipe C. M. (org.). Covid-19: meio ambiente e políticas 
públicas. $1^{\mathrm{a}}$. ed. São Paulo: Hucitec, p. 155-159, 2020. Disponível em: http://www.huciteceditora.com.br/_imagens/_downloads/Covid19\%20Meio\%20Ambiente\%20e\%20Politicas\%20Publicas.pdf?fbclid=IwAR2ulDD ouxOBDaU9junRx4c-4M53L-nj-GOFQmpfkv691d192HPgqrDjVO8. Acesso em: 19 de out. de 2020.

DESCARTES, René. Discurso do método. Porto Alegre: L\& PM, 2013. Tradução de Paulo Neves. - Porto Alegre: (L\& PM clássicos).

DUPAS, Gilberto. O mito do progresso. Revista Novos Estudos, Vol. 1, n ${ }^{0}$. 77, p. 73-89, 2007. Disponível em: http://novosestudos.com.br/produto/edicao77/\# home. Acesso em: 21 de out. de 2020.

LÖWY, Michael. crise ecológica, crise capitalista, crise de civilização: a alternativa ecossocialista. CADERNO CRH, Salvador, v. 26, nº. 67, jan./abr. p. 79-86, 2013. Dispoível em: https://www.scielo.br/pdf/ccrh/v26n67/ao6v26n67.pdf. Acesso em: 20 de out. de 2020.

FRANÇA, Helysson A; OLIVEIRA, Luizir de. vida e liberdade em Hans Jonas: pressuposto teóricos para uma filosofia da técnica. Revista Humus São Luís, vol. 6, n. $17, \quad$ p. $103-117, \quad 2016 . \quad$ Fonte: http://www.periodicoseletronicos.ufma.br/index.php/revistahumus/article/view/ 5469. Acesso em: 23 de out. de 2020.

FERNANDES, Maria de F. A. «O Princípio Responsabilidade» de Hans Jonas: Em busca dos fundamentos éticos da educação contemporânea. 2002. Dissertação (Mestrado em Filosofia da Educação). Faculdade de Letras da Universidade do Porto. Celorico de Basto, 2002. Disponível em: https://repositorio-aberto.up.pt/handle/10216/10874. Acesso em: 15 de out. de 2020.

JONAS, Hans. O princípio responsabilidade: ensaio de uma ética para uma civilização tecnológica. Tradução Marijane Lisboa; Luiz Barros Montez. Rio de Janeiro: Contraponto; Ed. PUC-Rio, 2006.

JUNGES, José R. Pandemia do Covid 19 e crise ambiental: questões críticas. Revista Pelicano, vol.6, p. 34-54, 2020. Disponível em: http://revistas.bibdigital.uccor.edu.ar/index.php/pelicano/issue/view/772/showT oc. Acesso em: 15 de nov. de 2020.

KOYRÉ, Alexandre. 4.ed. Do mundo fechado ao universo infinito. Tradução de Donaldson M. Garschagen. 4, ed. - Rio de Janeiro: Forense Universitária, 2006.

KOPENAWA, Davi; ALBERT, Bruce. A queda do céu: palavras de um xamã Yanomani. Tradução Beatriz Perrone-Moisés; prefácio Eduardo Viveiros de Castro. São Paulo: Companhia das Letras, 2015.

SANTOS, Boaventura de S. S. Um discurso sobre as Ciências. $7^{\text {a }}$ ed. Porto. Edições Afrontamento, 1995. 
VIANA, Wellistony Carvalho. A técnica sob o "Princípio Responsabilidade" de Hans Jonas. Pensando - Revista de Filosofia. Piaú, Vol. 1, No 2, 2010, p. 106-118. Disponível em: https://revistas.ufpi.br/index.php/pensando/article/view/548. Acesso em: 23 de out. de 2020.

ZATERKA, L. BARBOSA, G.L.A. Francis Bacon e a constituição do ideal científico moderno. In: MOURA, B. A; FORATO, T. C. M. (org.). Histórias das ciências, epistemologia, gênero e arte: ensaios para a formação de professores [online]. São Bernardo do Campo, SP: Editora UFABC. p. 195-215, 2017. Disponível em: http://books.scielo.org/id/8938t/pdf/moura-9788568576847.pdf. Acesso em: 10 de nov. de 2020.

WEBER, Max. Ensaios de Sociologia. Tradução: Waltensir Dutra. $5^{\text {a }}$ ed. Rio de Janeiro: LTC Editora, 1982.

WELZER, Harald. Guerras climáticas: por que mataremos e seremos mortos no século XXI. Tradução William Lagos. Geração Editorial, 2010. Disponível em: https://lelivros.love/book/download-guerras-climaticas-harald-welzer-em-epubmobi-e-pdf/. Acesso em: 20 de out. de 2020.

Recebido em: 26/11/2020. Aprovado em: 08/12/2020. Publicado em: 26/12/2020. 